\title{
Gender Differences in Coronary Artery Disease
}

\author{
Ryotaro Wake and Minoru Yoshiyama \\ Osaka City University Graduate School of Medicine, \\ Japan
}

\section{Introduction}

Coronary artery disease (CAD) is a leading cause of mortality and morbidity in most developed countries [1]. Many studies have found gender-related differences in the presentations, prevalence, and clinical outcomes of CAD [2-4]. CAD first presents itself in women approximately 10 years later than in men, most commonly after menopause [5]. The worldwide INTERHEART study, a large study of more than 52000 individuals with MI, first demonstrated that this approximate 8 to 10 year difference in age at onset holds widely around the world, across various socioeconomic, climatic, and cultural environments. Although coronary artery disease in general is manifestated earlier in less developed countries, the age gap in time of onset between men and women is universal (Table 1) [6].

\begin{tabular}{lll}
\hline Region & Median age, women & Median age, men \\
\hline Western Europe & $68(59-76)$ & $61(53-70)$ \\
Central and eastern Europe & $68(59-74)$ & $59(50-68)$ \\
North America & $64(52-75)$ & $58(49-68)$ \\
South America and Mexico & $65(56-73)$ & $59(50-68)$ \\
Australia and New Zealand & $66(59-74)$ & $58(50-67)$ \\
Middle East & $57(50-65)$ & $50(44-57)$ \\
Africa & $56(49-65)$ & $52(46-61)$ \\
South Asia & $60(50-66)$ & $52(45-60)$ \\
China and Hong Kong & $67(62-72)$ & $60(50-68)$ \\
Southeast Asia and Japan & $63(56-68)$ & $55(47-64)$ \\
\hline
\end{tabular}

Table 1. Comparison of age at first myocardial infarction among women and men across geographic regions: Effect of potentially modifiable risk factors associated with myocardial infarction in 52 countries (the INTERHEART study): Case-control study [6].

Compared to women, men present with ST-segment elevation myocardial infarction (MI) more often and have a higher prevalence of CAD adjusted for age $[7,8]$. However, younger women experience more adverse outcomes after MI and coronary artery bypass grafting surgery than men [9]. A greater proportion of women than men with MI die of sudden cardiac arrest before reaching hospital $[3,10]$. Previous reports have shown a $20 \%$ reduction in total mortality among patients randomized to exercise-based cardiac rehabilitation compared with controls receiving usual care [11]. The outcome was however similar between men and women, although only $20 \%$ of all participants were women in many 
reports. Women are less likely than men to participate in cardiac rehabilitation after acute MI [11].

The prevalence of microvascular angina is higher in women than men. Takotsubo cardiomyopathy is more prevalent in women than in men [12]. These findings indicate that gender difference may have an important influence on cardiovascular physiology and pathology $[13,14]$.

In many developing countries, a large budget is expended for the treatment of CAD, and it is necessary to minimize the influence of risk factors. The burden of CAD on women and the global economy will continue to increase [5]. In addition to population-based and macroeconomic interventions, interventions in individual patients are key to reducing the incidence of CAD globally [15]. Prevention of CAD is paramount to the health of every woman and every nation.

There have been numerous clinical trials that have a bearing on CAD prevention in women [16]. Women and men differ in their genetic complement by a single chromosome out of the 46 that are present in the human species. However, this single chromosomal difference affects both the expression of disease and the psychosocial and behavioral characteristics and work environments of individuals, which may reduce or increase the susceptibility to cardiovascular diseases.

In future, novel drugs for tailor-made therapy of CAD based on gender differences may be developed. This review discusses gender differences in the features of ischemic heart disease and the possibilities of future developments in treatments.

\section{Clinical risk factors of coronary artery disease in women}

It is important to classify women as being at high, intermediate, or low risk for CAD. Classification may be based on clinical criteria and the Framingham global risk score [17]. A woman found to have coronary calcification or increased carotid intimal thickness may be at low risk for $\mathrm{CAD}$ on the basis of the Framingham risk score, but she may be actually at intermediate or high risk for a future CAD event.

We should take several factors into consideration, including medical and lifestyle histories, Framingham risk score, family history of CAD, and other genetic conditions (e.g., familial hypercholesterolemia), since these affect the decisions about the aggressiveness of preventive therapy. Novel CAD risk factors (e.g., high-sensitivity C-reactive protein [18]) and novel screening technologies (e.g., coronary calcium scoring) should help guide preventive interventions. Further research is needed on the benefits, risks, and costs associated with such strategies. There are many unique opportunities for early detection of CAD in women; for example, in pregnancy, preeclampsia may be an early indicator of CAD risk $[19,20]$. In addition, maternal placental syndromes in combination with traditional cardiovascular risk factors, such as pre-pregnancy hypertension or diabetes mellitus, obesity, dyslipidemia, and metabolic syndrome, may be additive in defining CAD risk in women [19]. Future research should evaluate the potential for events or medical contact during unique phases in a woman's life, such as adolescence, pregnancy, and menopause, to 
identify women at high risk, and determine the effectiveness of preventive interventions during critical periods.

The diagnosis of CAD in women presents challenges not observed in case of men. Differences in the epidemiology of CAD between men and women show that women are generally at a lower risk than their male counterparts until the seventh decade of life. For both asymptomatic and symptomatic women, the choice of initial test is guided by classification into low, intermediate, or high pretest risk categories. Asymptomatic intermediate-risk women have lower event rates. In symptomatic women, noninvasive diagnostic studies (exercise electrocardiography (ECG) and cardiac imaging studies) are recommended for those who are at an intermediate to high pretest likelihood of CAD [21]. Therapeutic decision-making is guided by the extent and severity of inducible ischemia. Thus, referral of low-likelihood women (for example, premenopausal women with less than one risk factor and non-anginal/atypical symptoms) will be associated with a high rate of false positives.

Smoking is an important risk factor for vascular diseases. Vascular disease risk was most quickly reduced by cessation of smoking compared with other associated factors. The beneficial effect of quitting on the risk for death from CHD was realized within 5 years, whereas the risks for death from chronic obstructive pulmonary disease and lung cancer did not approach those of women who had never smoked until the age of 20 and 30 years, respectively [22]. It may never be too late for women to quit smoking in order to reduce the risk for vascular diseases.

A blood pressure-lowering treatment provided similar protection against major cardiovascular events in men and women [23].

\section{Features of coronary artery pathology in women}

Men have a greater burden of atheroma and eccentric atheroma in coronary arteries compared to women. A study reported that plaque rupture in patients with sudden coronary death was more frequent in men than in women [24].

Men have more severe structural and functional abnormalities in the epicardial coronary arteries than women. These factors may influence the higher incidence rates of CAD and STsegment MI (STEMI) in men compared to women. With regard to the lower cardiac event rate in female patients, several mechanisms have been proposed to explain the cardioprotective effect of sex hormones in women [13]. We show the effect of sex hormones in ischemic heart disease in table 2.

Women had lower rates of obstructive CAD at angiography when evaluated for symptoms suggestive of myocardial ischemia [25]. Among angiographic CAD patients, atheroma volume in women is less than that in men, despite the presence of more cardiovascular risk factors in women. Women had slightly lower coronary vasodilator reserve even with normal coronary angiographic results [26]. Endothelial-independent microvascular dysfunction was an independent predictor of adverse outcomes in patients with mild CAD [27]. It has been suggested that the mechanism of myocardial ischemia in women may be localized to the microvascular coronary arteries and that abnormal microvascular function may have prognostic implications [28]. 


\begin{tabular}{|c|c|c|}
\hline & Favorable & Unfavorable \\
\hline Lipids & $\begin{array}{l}\downarrow \text { LDL - cholesterol } \\
\uparrow \text { HDL - cholesterol }\end{array}$ & $\mathbf{\uparrow}_{\text {Trigriceride }}$ \\
\hline $\begin{array}{l}\text { Coagulation } \\
\text { Fibrinolysis }\end{array}$ & $\begin{array}{l}\downarrow \text { PAI-1 } \\
\downarrow \text { Fibrinogen }\end{array}$ & $\begin{array}{l}\uparrow \text { Factor VII } \\
\downarrow \text { AT III }\end{array}$ \\
\hline $\begin{array}{l}\text { Inflammation } \\
\text { Adhesion }\end{array}$ & $\downarrow$ Adhesion molecules & 个 CRP \\
\hline $\begin{array}{l}\text { Endothelial function } \\
\text { Blood pressure }\end{array}$ & $\begin{array}{l}\downarrow \text { ACE activity } \\
\uparrow \text { Nitric oxide } \\
\downarrow \text { Endothelin-1 } \\
\uparrow \text { Plasminogen I2 } \\
\downarrow \text { VSMC migration, } \\
\text { proliferation }\end{array}$ & $\hat{\uparrow}$ Angiotensinogen \\
\hline
\end{tabular}

PAI-1: plasminogen activator inhibitor-1, AT III: antithrombin III, ACE: angiotensinogen converting enzyme, VSMC: vascular smooth muscle cell.

Table 2. Effect of estrogen on atherosclerosis.

\section{Takotsubo cardiomyopathy}

Takotsubo cardiomyopathy (or transient LV apical ballooning syndrome) is more prevalent in women than in men. Because the onset of this syndrome is often preceded by emotional or physical stress, catecholamine-mediated multivessel epicardial spasm, microvascular coronary spasm, or possible direct catecholamine-mediated myocyte injury have been advocated as possible pathophysiological mechanisms [12]. Electrocardiographic findings are like myocardial infarction. The left ventricular wall motion is akinetic from the middle to apex of the left ventricle on the left ventriculography and echocardiography [29]. The epicardial coronary artery stenosis is absent in the coronary angiography. Cardiac magnetic resonance can be useful for differentiating apical ballooning syndrome from an acute coronary event [12]. Late gadolinium enhancement in this setting represents a disproportionate expansion of extracellular matrix with increased collagen I deposition on immunohistochemical tissue staining [30].

\section{Diagnosis and prognosis}

\subsection{Electrocardiography}

Changes in ECG during exercise have been reported to be of diminished accuracy in women as a result of more frequent changes in resting ST-T wave, lower ECG voltage, and hormonal factors such as endogenous estrogen in premenopausal women and hormone replacement therapy in postmenopausal women [31-33]. In a meta-analysis of exercise ECG studies in women, sensitivity was $61 \%$ and specificity was $70 \%$, compared to $72 \%$ and $77 \%$, 
respectively, in men [21]. From a cohort of symptomatic women who were referred for exercise treadmill testing followed by coronary angiography, significant coronary stenosis (more than $75 \%$ ) was observed in 19\%, 35\%, and 89\% of low-, moderate-, and high-risk women, respectively, based on Duke treadmill score risk categories [34].

Maximal exercise capacity and heart rate recovery measurements can aid in estimation of near- and long-term outcome in large cohorts of women [35]. Recent reports have noted that a simple measure such as heart rate recovery (at 1 or $2 \mathrm{~min}$ after exercise) have substantial prognostic value.

Women engage less often in physical exercise programs, have lower functional capacity, and show a greater functional decline during their menopausal years. Because of their lower work capacity on exercise tests (on average $5-7 \mathrm{~min}$ ) as a result of premature peripheral fatigue, it is difficult to provoke myocardial ischemia [36]. Women who exercise less than 5 metabolic equivalents (METs) are at an increased risk for death [37]. Women expected to perform less than 5 METs may be better evaluated by pharmacological stress imaging. However, women who have inducible ischemia at low workloads (less than 5 METs) have a higher likelihood of obstructive CAD and may be referred for coronary angiography.

The exercise ECG test has a high negative predictive value in women with a low pretest probability of CAD and a low-risk Duke treadmill score [21]. The diagnostic and prognostic accuracy of the exercise ECG stress test in symptomatic women with suspected CAD is increased by the inclusion of additional parameters in the interpretation of the ST-segment response to exercise.

\subsection{Echocardiography}

Stress echocardiography can provide information about the presence of left ventricular systolic or diastolic dysfunction, valvular heart disease, and the extent of infarction and stress-induced ischemia. Exercise echocardiography may be performed with a treadmill or by supine or upright bicycle exercise. Exercise stress echocardiography is a physiological investigation and the most widely available method for evaluation of CAD. However, exercise capacity is often impaired in aged or diabetic patients and the workload required to produce stress-induced myocardial ischemia might not be achieved by such patients.

Stress echocardiography provides significantly higher specificity and accuracy than the standard exercise ECG testing in women [38].

Stress echocardiography has demonstrated good diagnostic accuracy for detecting or excluding significant CAD, with a mean sensitivity of $81 \%$, specificity of $86 \%$, and an overall accuracy of $84 \%$ [38-41]. There appears to be no significant effect of gender on the diagnostic accuracy of exercise echocardiography.

A study of dobutamine stress echocardiography (DSE) revealed an overall sensitivity of $80 \%$ and specificity of $84 \%$ [39]. To exercise stress echocardiography, DSE appears to have similar diagnostic accuracy in detecting CAD in both women and men.

Cardiac events occur less frequently in women than in men. This difference is compatible with the lower prevalence and lesser sensitivity of detection of CAD in women compared to men. No gender differences have been reported in the prognostic value of exercise stress echocardiography in a large population. 
The low specificity of exercise ECG testing in women, especially in young and middle-aged women, may lead to a higher rate of unnecessary angiography and higher expense, particularly if stress imaging is not used before coronary angiography in a sequential testing strategy.

Stress echocardiography with exercise or dobutamine is an effective and highly accurate noninvasive means of detecting ischemic heart disease and risk-stratifying symptomatic women with an intermediate to high pretest likelihood of CAD. Stress echocardiography provides incremental value over exercise ECG and clinical variables in women with suspected or known coronary heart disease. Stress echocardiography is recommended for symptomatic women with an intermediate or high pretest probability of CAD (women with suspected CAD must also have an abnormal resting ECG). Previous reports demonstrated that pharmacological stress echocardiography provides independent prognostic information in both men and women $[42,43]$.

\subsection{Myocardial perfusion}

Gated myocardial perfusion single-photon emission computed tomography (SPECT) is a nuclear-based technique that provides a combination of test elements that are used to diagnose and risk-stratify women. Myocardial perfusion imaging, however, has been reported to have technical limitations in women, including false-positive results due to breast attenuation and small left ventricular chamber size [44].

The accuracy of 201Tl SPECT imaging, for example, is reduced in patients with small hearts, and these patients are more likely to be women than men. When $201 \mathrm{Tl}$ is used as the radioisotope in women, false-positive test results may occur due to soft tissue attenuation (e.g., breast attenuation) in the anterior and anterolateral segments [44].

For women, the lower-energy isotope $201 \mathrm{Tl}$ has been largely supplanted by technetiumbased imaging agents that improve accuracy. In comparing the diagnostic accuracy of $201 \mathrm{Tl}$ with gated 99mTc-sestamibi SPECT in women, the sensitivity for detecting CAD was 80\%, and test specificity improved dramatically from $67 \%$ for $201 \mathrm{Tl}$ to $92 \%$ for gated $99 \mathrm{mTc}$ sestamibi SPECT [45].

Pharmacological stress SPECT also merits consideration, given the higher incidence of decreased exercise capacity and advanced age for women, as discussed previously $[44,46]$. Vasodilator pharmacological stress perfusion imaging has been shown to be more accurate than exercise perfusion imaging in identification of CAD in both men and women with left bundle-branch block [46]. Adenosine 99mTc-sestamibi imaging was reported to have $91 \%$ sensitivity and $86 \%$ specificity for detecting significant coronary artery stenoses of more than $50 \%$ [47].

Myocardial perfusion imaging has powerful predictive value with regard to the development of subsequent cardiac death or MI or the need for coronary revascularization [48-50], regardless of sex [36]. Prognosis worsens commensurate with the number of vascular territories involved, with 3-year survival rates ranging from $99 \%$ for women without ischemia to $85 \%$ in women who had three-vessel ischemia [36].

In addition, pharmacological stress was recently shown to be effective in the risk stratification of diabetic women with suspected and known CAD. The CAD mortality for 
non-diabetic women with a moderately abnormal scan was $2.8 \%$ compared with $4.1 \%$ in diabetic women [48].

\section{Treatment}

Studies have shown that percutaneous coronary intervention (PCI) is a more effective reperfusion strategy for acute coronary syndrome than intravenous thrombolysis [51]. The advantage of primary PCI over thrombolytic therapy was greater for women than men [52]. Primary PCI reduced the risk of intracranial bleeding and improved survival in women [53].

Mortality from acute MI (AMI) was higher in women than in men, consistent with the results of most previous studies [52,54,55]. This poorer outcome in women was likely related to the facts that compared to men, women with AMI were older, underwent PCI less frequently, and had higher incidences of coronary risk factors, such as hyperlipidemia, diabetes mellitus, and hypertension.

The use of a drug-eluting stent makes the outcome after PCI better than that after the use of a bare metal stent. There is no difference between men and women in the outcome [56].

On the other hand, the most important benefit of PCI in chronic stable CAD may be the relief of symptoms [57]. Statin therapy is effective for chronic stable CAD [58].

Women experience more bleeding than men with antiplatelet therapy and/or anticoagulant therapy as they often have a smaller body size, resulting in excessive dosing. These agents should be used with regard to the patient's body size [59]. In a primary prevention trial in women, aspirin lowered the risk of stroke without affecting the risk of MI. On the other hand, in men, aspirin lowered the risk of MI without affecting the risk of stroke $[60,61]$.

Angiotensin-converting enzyme inhibitors, angiotensin receptor blockers and warfarin for blood pressure control are contraindicated in women contemplating pregnancy and in those who are pregnant.

The perception of the risks and benefits of hormone replacement therapy (HRT) and the time when the therapy should be initiated has changed dramatically since the publication of the Women's Health Initiative trial in 2002. This study of women in whom HRT was initiated on average 13 years after menopause did not reveal long-term benefits for cardiovascular outcomes [62]. However, combined HRT started many years after menopause can improve health-related quality of life [63].

Reports show $20 \%$ reduction in total mortality among patients randomized to exercise-based cardiac rehabilitation compared with controls receiving usual care. The outcome is similar between men and women, although only $20 \%$ of all participants were women in many reports. Women are less likely than men to participate in cardiac rehabilitation after acute MI [11]. This may be one reason for the poor outcome in women with AMI. Cardiac rehabilitation should be recommended to more women after AMI.

\section{Conclusions}

Appropriate diagnosis, prevention, and treatment will improve the care of all CAD patients. Since there are gender differences in ischemic heart disease, it is necessary to consider these 
differences when examining men and women with ischemic heart disease. We have found many gender differences in CAD. The development of novel drugs and therapeutic methods for tailor-made therapy of CAD based on gender differences is required.

\section{References}

[1] Rosamond, W. et al. (2007) Heart disease and stroke statistics--2007 update: a report from the American Heart Association Statistics Committee and Stroke Statistics Subcommittee. Circulation 115 (5), e69-171

[2] Bairey Merz, C.N. et al. (2006) Insights from the NHLBI-Sponsored Women's Ischemia Syndrome Evaluation (WISE) Study: Part II: gender differences in presentation, diagnosis, and outcome with regard to gender-based pathophysiology of atherosclerosis and macrovascular and microvascular coronary disease. J Am Coll Cardiol 47 (3 Suppl), S21-29

[3] Shaw, L.J. et al. (2006) Insights from the NHLBI-Sponsored Women's Ischemia Syndrome Evaluation (WISE) Study: Part I: gender differences in traditional and novel risk factors, symptom evaluation, and gender-optimized diagnostic strategies. J Am Coll Cardiol 47 (3 Suppl), S4-S20

[4] Wake, R. et al. (2007) Effects of gender on prognosis of patients with known or suspected coronary artery disease undergoing contrast-enhanced dobutamine stress echocardiography. Circ J 71 (7), 1060-1066

[5] Yusuf, S. et al. (2001) Global burden of cardiovascular diseases: part I: general considerations, the epidemiologic transition, risk factors, and impact of urbanization. Circulation 104 (22), 2746-2753

[6] Yusuf, S. et al. (2004) Effect of potentially modifiable risk factors associated with myocardial infarction in 52 countries (the INTERHEART study): case-control study. Lancet 364 (9438), 937-952

[7] Heer, T. et al. (2002) Gender differences in acute myocardial infarction in the era of reperfusion (the MITRA registry). Am J Cardiol 89 (5), 511-517

[8] Kosuge, M. et al. (2006) Differences between men and women in terms of clinical features of ST-segment elevation acute myocardial infarction. Circ J 70 (3), 222-226

[9] Vaccarino, V. et al. (2002) Sex differences in hospital mortality after coronary artery bypass surgery: evidence for a higher mortality in younger women. Circulation 105 (10), 1176-1181

[10] Thom, T. et al. (2006) Heart disease and stroke statistics--2006 update: a report from the American Heart Association Statistics Committee and Stroke Statistics Subcommittee. Circulation 113 (6), e85-151

[11] Taylor, R.S. et al. (2004) Exercise-based rehabilitation for patients with coronary heart disease: systematic review and meta-analysis of randomized controlled trials. Am J Med 116 (10), 682-692

[12] Wittstein, I.S. et al. (2005) Neurohumoral features of myocardial stunning due to sudden emotional stress. N Engl J Med 352 (6), 539-548

[13] Mendelsohn, M.E. and Karas, R.H. (2005) Molecular and cellular basis of cardiovascular gender differences. Science 308 (5728), 1583-1587

[14] Pepine, C.J. (2004) Ischemic heart disease in women: facts and wishful thinking. J Am Coll Cardiol 43 (10), 1727-1730 
[15] Strong, K. et al. (2005) Preventing chronic diseases: how many lives can we save? Lancet 366 (9496), 1578-1582

[16] Kotseva, K. et al. (2009) Cardiovascular prevention guidelines in daily practice: a comparison of EUROASPIRE I, II, and III surveys in eight European countries. Lancet 373 (9667), 929-940

[17] (2002) Third Report of the National Cholesterol Education Program (NCEP) Expert Panel on Detection, Evaluation, and Treatment of High Blood Cholesterol in Adults (Adult Treatment Panel III) final report. Circulation 106 (25), 3143-3421

[18] Ridker, P.M. et al. (2009) Reduction in C-reactive protein and LDL cholesterol and cardiovascular event rates after initiation of rosuvastatin: a prospective study of the JUPITER trial. Lancet 373 (9670), 1175-1182

[19] Ray, J.G. et al. (2005) Cardiovascular health after maternal placental syndromes (CHAMPS): population-based retrospective cohort study. Lancet 366 (9499), 17971803

[20] Wilson, B.J. et al. (2003) Hypertensive diseases of pregnancy and risk of hypertension and stroke in later life: results from cohort study. Bmj 326 (7394), 845

[21] Gibbons, R.J. et al. (2002) ACC/AHA 2002 guideline update for exercise testing: summary article: a report of the American College of Cardiology/American Heart Association Task Force on Practice Guidelines (Committee to Update the 1997 Exercise Testing Guidelines). Circulation 106 (14), 1883-1892

[22] Kenfield, S.A. et al. (2008) Smoking and smoking cessation in relation to mortality in women. Jama 299 (17), 2037-2047

[23] Turnbull, F. et al. (2008) Do men and women respond differently to blood pressurelowering treatment? Results of prospectively designed overviews of randomized trials. Eur Heart J 29 (21), 2669-2680

[24] Virmani, R. et al. (2000) Lessons from sudden coronary death: a comprehensive morphological classification scheme for atherosclerotic lesions. Arterioscler Thromb Vasc Biol 20 (5), 1262-1275

[25] Sharaf, B.L. et al. (2001) Detailed angiographic analysis of women with suspected ischemic chest pain (pilot phase data from the NHLBI-sponsored Women's Ischemia Syndrome Evaluation [WISE] Study Angiographic Core Laboratory). Am J Cardiol 87 (8), 937-941; A933

[26] Kern, M.J. et al. (1996) Variations in normal coronary vasodilatory reserve stratified by artery, gender, heart transplantation and coronary artery disease. J Am Coll Cardiol 28 (5), 1154-1160

[27] Britten, M.B. et al. (2004) Microvascular dysfunction in angiographically normal or mildly diseased coronary arteries predicts adverse cardiovascular long-term outcome. Coron Artery Dis 15 (5), 259-264

[28] Johnson, B.D. et al. (2004) Prognosis in women with myocardial ischemia in the absence of obstructive coronary disease: results from the National Institutes of HealthNational Heart, Lung, and Blood Institute-Sponsored Women's Ischemia Syndrome Evaluation (WISE). Circulation 109 (24), 2993-2999

[29] Hurst, R.T. et al. (2006) Transient midventricular ballooning syndrome: a new variant. J Am Coll Cardiol 48 (3), 579-583

[30] Rolf, A. et al. (2009) Immunohistological basis of the late gadolinium enhancement phenomenon in tako-tsubo cardiomyopathy. Eur Heart J 30 (13), 1635-1642 
[31] Rosano, G.M. et al. (2000) Natural progesterone, but not medroxyprogesterone acetate, enhances the beneficial effect of estrogen on exercise-induced myocardial ischemia in postmenopausal women. J Am Coll Cardiol 36 (7), 2154-2159

[32] Schulman, S.P. et al. (2002) Effects of acute hormone therapy on recurrent ischemia in postmenopausal women with unstable angina. J Am Coll Cardiol 39 (2), 231-237

[33] Waters, D.D. et al. (2004) Women's Ischemic Syndrome Evaluation: current status and future research directions: report of the National Heart, Lung and Blood Institute workshop: October 2-4, 2002: Section 4: lessons from hormone replacement trials. Circulation 109 (6), e53-55

[34] Alexander, K.P. et al. (1998) Value of exercise treadmill testing in women. J Am Coll Cardiol 32 (6), 1657-1664

[35] Mora, S. et al. (2003) Ability of exercise testing to predict cardiovascular and all-cause death in asymptomatic women: a 20-year follow-up of the lipid research clinics prevalence study. Jama 290 (12), 1600-1607

[36] Marwick, T.H. et al. (1999) The noninvasive prediction of cardiac mortality in men and women with known or suspected coronary artery disease. Economics of Noninvasive Diagnosis (END) Study Group. Am J Med 106 (2), 172-178

[37] Hlatky, M.A. et al. (1989) A brief self-administered questionnaire to determine functional capacity (the Duke Activity Status Index). Am J Cardiol 64 (10), 651-654

[38] Cheitlin, M.D. et al. (2003) ACC/AHA/ASE 2003 guideline update for the clinical application of echocardiography: summary article: a report of the American College of Cardiology/American Heart Association Task Force on Practice Guidelines (ACC/AHA/ASE Committee to Update the 1997 Guidelines for the Clinical Application of Echocardiography). Circulation 108 (9), 1146-1162

[39] Kim, C. et al. (2001) Pharmacologic stress testing for coronary disease diagnosis: A meta-analysis. Am Heart J 142 (6), 934-944

[40] Kwok, Y. et al. (1999) Meta-analysis of exercise testing to detect coronary artery disease in women. Am J Cardiol 83 (5), 660-666

[41] Lewis, J.F. et al. (1999) Dobutamine stress echocardiography in women with chest pain. Pilot phase data from the National Heart, Lung and Blood Institute Women's Ischemia Syndrome Evaluation (WISE). J Am Coll Cardiol 33 (6), 1462-1468

[42] Biagini, E. et al. (2005) Seven-year follow-up after dobutamine stress echocardiography: impact of gender on prognosis. J Am Coll Cardiol 45 (1), 93-97

[43] Cortigiani, L. et al. (1998) Prognostic value of pharmacological stress echocardiography in women with chest pain and unknown coronary artery disease. J Am Coll Cardiol 32 (7), 1975-1981

[44] Mieres, J.H. et al. (2003) American Society of Nuclear Cardiology consensus statement: Task Force on Women and Coronary Artery Disease--the role of myocardial perfusion imaging in the clinical evaluation of coronary artery disease in women [correction]. J Nucl Cardiol 10 (1), 95-101

[45] Taillefer, R. et al. (1997) Comparative diagnostic accuracy of Tl-201 and Tc-99m sestamibi SPECT imaging (perfusion and ECG-gated SPECT) in detecting coronary artery disease in women. J Am Coll Cardiol 29 (1), 69-77

[46] Klocke, F.J. et al. (2003) ACC/AHA/ASNC guidelines for the clinical use of cardiac radionuclide imaging--executive summary: a report of the American College of Cardiology/American Heart Association Task Force on Practice Guidelines 
(ACC/AHA/ASNC Committee to Revise the 1995 Guidelines for the Clinical Use of Cardiac Radionuclide Imaging). Circulation 108 (11), 1404-1418

[47] Amanullah, A.M. et al. (1997) Identification of severe or extensive coronary artery disease in women by adenosine technetium-99m sestamibi SPECT. Am J Cardiol 80 (2), 132-137

[48] Berman, D.S. et al. (2003) Adenosine myocardial perfusion single-photon emission computed tomography in women compared with men. Impact of diabetes mellitus on incremental prognostic value and effect on patient management. J Am Coll Cardiol 41 (7), 1125-1133

[49] Galassi, A.R. et al. (2001) Incremental prognostic value of technetium-99m-tetrofosmin exercise myocardial perfusion imaging for predicting outcomes in patients with suspected or known coronary artery disease. Am J Cardiol 88 (2), 101-106

[50] Sharir, T. et al. (1999) Incremental prognostic value of post-stress left ventricular ejection fraction and volume by gated myocardial perfusion single photon emission computed tomography. Circulation 100 (10), 1035-1042

[51] Weaver, W.D. et al. (1997) Comparison of primary coronary angioplasty and intravenous thrombolytic therapy for acute myocardial infarction: a quantitative review. Jama 278 (23), 2093-2098

[52] Tamis-Holland, J.E. et al. (2004) Benefits of direct angioplasty for women and men with acute myocardial infarction: results of the Global Use of Strategies to Open Occluded Arteries in Acute Coronary Syndromes Angioplasty (GUSTO II-B) Angioplasty Substudy. Am Heart J 147 (1), 133-139

[53] Stone, G.W. et al. (1995) Comparison of in-hospital outcome in men versus women treated by either thrombolytic therapy or primary coronary angioplasty for acute myocardial infarction. Am J Cardiol 75 (15), 987-992

[54] Lansky, A.J. et al. (2005) Gender differences in outcomes after primary angioplasty versus primary stenting with and without abciximab for acute myocardial infarction: results of the Controlled Abciximab and Device Investigation to Lower Late Angioplasty Complications (CADILLAC) trial. Circulation 111 (13), 1611-1618

[55] Vakili, B.A. et al. (2001) Sex-based differences in early mortality of patients undergoing primary angioplasty for first acute myocardial infarction. Circulation 104 (25), 30343038

[56] Moses, J.W. et al. (2003) Sirolimus-eluting stents versus standard stents in patients with stenosis in a native coronary artery. N Engl J Med 349 (14), 1315-1323

[57] Trikalinos, T.A. et al. (2009) Percutaneous coronary interventions for non-acute coronary artery disease: a quantitative 20-year synopsis and a network metaanalysis. Lancet 373 (9667), 911-918

[58] Baigent, C. et al. (2005) Efficacy and safety of cholesterol-lowering treatment: prospective meta-analysis of data from 90,056 participants in 14 randomised trials of statins. Lancet 366 (9493), 1267-1278

[59] Alexander, K.P. et al. (2006) Sex differences in major bleeding with glycoprotein IIb/IIIa inhibitors: results from the CRUSADE (Can Rapid risk stratification of Unstable angina patients Suppress ADverse outcomes with Early implementation of the ACC/ AHA guidelines) initiative. Circulation 114 (13), 1380-1387

[60] (2009) Aspirin for the prevention of cardiovascular disease: U.S. Preventive Services Task Force recommendation statement. Ann Intern Med 150 (6), 396-404 
[61] Ridker, P.M. et al. (2005) A randomized trial of low-dose aspirin in the primary prevention of cardiovascular disease in women. N Engl J Med 352 (13), 1293-1304

[62] Rossouw, J.E. et al. (2002) Risks and benefits of estrogen plus progestin in healthy postmenopausal women: principal results From the Women's Health Initiative randomized controlled trial. Jama 288 (3), 321-333

[63] Welton, A.J. et al. (2008) Health related quality of life after combined hormone replacement therapy: randomised controlled trial. Bmj 337, a1190 


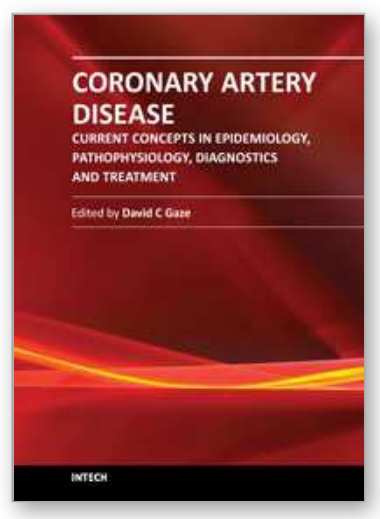

\author{
Coronary Artery Disease - Current Concepts in Epidemiology, \\ Pathophysiology, Diagnostics and Treatment \\ Edited by Dr. David Gaze
}

ISBN 978-953-51-0262-5

Hard cover, 272 pages

Publisher InTech

Published online 16, March, 2012

Published in print edition March, 2012

Cardiovascular disease is ranked as the leading cause of death world wide, responsible for 17.1 million deaths globally each year. Such numbers are often difficult to comprehend. Heart disease kills one person every 34 seconds in the USA alone. Although the leading killer, the incidence of cardiovascular disease has declined in recent years due to a better understanding of the pathology, implementation of lipid lowering therapy new drug regimens including low molecular weight heparin and antiplatelet drugs such as glycoprotein Ilb/llla receptor inhibitors and acute surgical intervention. The disease burden has a great financial impact on global healthcare systems and major economic consequences for world economies. This text aims to deliver the current understanding of coronary artery disease and is split into three main sections: 1 . Epidemiology and pathophysiology of coronary artery disease 2 . Coronary artery disease diagnostics and 3 . Treatment regimens for coronary artery disease

\title{
How to reference
}

In order to correctly reference this scholarly work, feel free to copy and paste the following:

Ryotaro Wake and Minoru Yoshiyama (2012). Gender Differences in Coronary Artery Disease, Coronary Artery Disease - Current Concepts in Epidemiology, Pathophysiology, Diagnostics and Treatment, Dr. David Gaze (Ed.), ISBN: 978-953-51-0262-5, InTech, Available from: http://www.intechopen.com/books/coronaryartery-disease-current-concepts-in-epidemiology-pathophysiology-diagnostics-and-treatment/genderdifferences-in-coronary-artery-diseases

\section{INTECH}

open science | open minds

\section{InTech Europe}

University Campus STeP Ri

Slavka Krautzeka 83/A

51000 Rijeka, Croatia

Phone: +385 (51) 770447

Fax: +385 (51) 686166

www.intechopen.com

\section{InTech China}

Unit 405, Office Block, Hotel Equatorial Shanghai

No.65, Yan An Road (West), Shanghai, 200040, China

中国上海市延安西路65号上海国际贵都大饭店办公楼 405 单元

Phone: +86-21-62489820

Fax: $+86-21-62489821$ 
(C) 2012 The Author(s). Licensee IntechOpen. This is an open access article distributed under the terms of the Creative Commons Attribution 3.0 License, which permits unrestricted use, distribution, and reproduction in any medium, provided the original work is properly cited. 